Article

\title{
Energy Trading with Electric Vehicles in Smart Campus Parking Lots
}

\author{
Mohamed A. Ahmed ${ }^{1,2, * \mathbb{D}}$ and Young-Chon Kim ${ }^{3, *}$ \\ 1 Department of Electronic Engineering, Universidad Técnica Federico Santa María, Valparaíso 2390123, Chile \\ 2 Department of Communications and Electronics, Higher Institute of Engineering \& Technology-King \\ Marriott, Alexandria 23713, Egypt \\ 3 Department of Computer Engineering and Smart Grid Research Center, Chonbuk National University, \\ Jeonju 54896, Korea \\ * $\quad$ Correspondence: mohamed@jbnu.ac.kr (M.A.A.); yckim@jbnu.ac.kr (Y.-C.K.); Tel.: +82-63-270-2413 (Y.-C.K.)
}

Received: 7 September 2018; Accepted: 25 September 2018; Published: 27 September 2018

check for updates

\begin{abstract}
Energy trading with electric vehicles provides opportunities to eliminate the high peak demand for electric vehicle charging while providing cost saving and profits for all participants. This work aims to design a framework for local energy trading with electric vehicles in smart parking lots where electric vehicles are able to exchange energy through buying and selling prices. The proposed architecture consists of four layers: the parking energy layer, data acquisition layer, communication network layer, and market layer. Electric vehicles are classified into three different types: seller electric vehicles (SEVs) with an excess of energy in the battery, buyer electric vehicles (BEVs) with lack of energy in the battery, and idle electric vehicles (IEVs). The parking lot control center (PLCC) plays a major role in collecting all available offer/demand information among parked electric vehicles. We propose a market mechanism based on the Knapsack Algorithm (KPA) to maximize the PLCC profit. Two cases are considered: electric vehicles as energy sellers and the PLCC as an energy buyer, and electric vehicles as energy buyers and the PLCC as an energy seller. A realistic parking pattern of a parking lot on a university campus is considered as a case study. Different scenarios are investigated with respect to the number of electric vehicles and amount of energy trading. The proposed market mechanism outperforms the conventional scheme in view of costs and profits.
\end{abstract}

Keywords: electric vehicle; energy trading; smart parking lot; energy market

\section{Introduction}

The grid integration of electric vehicles represents a unique and complex problem for the distribution power system. This is due to the fact that electric vehicles act as loads while charging, energy storage systems during the idle state, and distributed energy sources while discharging. Different schemes have been considered in order to coordinate the charging/discharging process of electric vehicles including grid control using incentives and time-varying prices supported by the grid operator [1]. In South Korea, Korea Electric Power Corporation (KEPCO) is the sole electric power provider. The current process of energy transactions in KEPCO prohibits direct energy trading between prosumers and consumers. Therefore, all energy transactions among consumers and prosumers must go through KEPCO [2]. As the penetration rate and the grid integration of renewable energy sources (RES) such as photovoltaic, energy storage systems, and electric vehicles are continuously increasing, more and more energy consumers are becoming energy prosumers. Energy prosumers are able to generate part of their usage energy locally using RES while sharing the surplus energy with other consumers [3]. Considering RES and the surplus energy of prosumers, the excess energy of prosumers 
can support the power grid during peak hours. However, there is a need for a new market model that enables energy trading between consumers and prosumers in the electric distribution system [4]. The new market model should provide various promising advantages in the distribution power systems including improved system efficiency, reduced system operation costs, and deferral of systems upgrade. However, the realization of the new market model will require a reliable communication network to support the real-time information exchange among electric vehicles. Considering the increasing number of electric vehicles, the system should be scalable to handle a large number of energy transactions among electric vehicles as well as maintain security and privacy for end user data.

Peer-to-peer energy trading is a new energy trading arrangement between consumers and prosumers in the distribution power system. The authors in Ref. [5] presented a survey on energy trading in the smart grid in view of enabling technologies, required frameworks, and desired outcomes. The authors highlighted the key enabling technologies that are required for energy trading including an energy storage system, renewable generation, electric vehicles, and communication. In Ref. [6], the authors provided a review of existing peer-to-peer energy trading projects. Some of the energy trading projects have focused on building business models and platforms to support energy trading among members. Examples of these projects are those done by Vandebron, Picl, and the Sonnen Community. Other projects have targeted the information and communication technologies (ICT) for energy trading such as the PeerEnergyCloud project and the Smart Watts project.

With respect to electric vehicles, the authors in Ref. [7] presented a novel energy trading method between two sets of electric vehicles. The first set includes drivers who can complete their daily activity with an excess of energy in their batteries. The second set includes drivers who need intermediate charging to complete their daily activities. Considering the grid price and vehicles' mobility, an aggregator is considered to determine the trading price, and vehicles with excess energy are allocated with vehicles that need to be charged at the same time and in the same area. The authors in Ref. [8] proposed three representative market models for peer-to-peer energy trading in a community microgrid with photovoltaic systems. The three market models are bill sharing, mid-market rate, and the auction-based pricing strategy.

Energy trading with electric vehicles is expected to play an important role in the future distribution power system supported by individual charging stations in home garages, public/private parking lots, and fast charging stations. This work focuses on energy trading with electric vehicles in smart parking lots. Smart parking lots are smart places that are capable of supporting both parking and charging services for electric vehicles during their parking time for a price [9]. With respect to the electric vehicle owner, the main objective is to charge an electric vehicle as quickly as possible considering a low charging cost without considering the status of other electric vehicles nor the electricity price or grid condition. On the contrary, the main objective of retailers and the parking lot operator is to maximize the net profit. Thus, market mechanisms are different based on actors (parking lot operator, retailers, customers, etc.) and the scale of the electric vehicle system (home, parking lots, fast charging stations, etc.). The desired outcome of buying energy from another electric vehicle rather than the main power grid may include economic benefits for owners such as cost minimization. However, there are many operational benefits for utilities such as reduced dependence on the power grid, decreased transmission losses, improved system efficiency, and balance between energy demand and supply [10].

Most of the previous research has focused on the grid integration of electric vehicles and how to mitigate the impact of electric vehicle charging on the distribution power system; however, this work focuses on energy trading with electric vehicles in smart parking lots. During parking time, owners of electric vehicles can invest their batteries in energy trading with the parking lot operator or other electric vehicles by selling the surplus energy in their battery. During the on-peak period, the parking lot operator can get power from electric vehicles at a lower price compared with the grid wholesale price. Also, the owners of electric vehicles can charge their electric vehicles at a low price during off-peak time and resell it at a higher price during the on-peak period. There is a need for a new 
framework for energy trading between electric vehicles and the parking lot operator to facilitate the new parking lot market operation. The main contributions of this work are:

- A framework for energy trading with electric vehicles in smart parking lots is designed.

- A four-layered architecture for energy trading in smart parking lots is proposed. It consists of a parking energy layer, a data acquisition layer, a communication network layer, and a market layer.

- A market mechanism based on the Knapsack Algorithm is proposed to maximize the profit of the parking lot operator.

- A real case study with a realistic parking pattern of a parking lot on a university campus is considered.

This paper is structured as follows. We propose a four-layered architecture for energy trading with electric vehicles in smart parking lots in Section 2. In Section 3, we develop a market mechanism for energy trading based on the Knapsack Algorithm (KPA). Section 4 provides the performance evaluation of a real case study of a university campus. Finally, Section 5 concludes the paper and gives directions for future work.

\section{Proposed System Architecture for Energy Trading in a Smart Parking Lot}

Smart parking is considered to be a typical cyber and physical system. In order to manage the grid integration of electric vehicles and minimize the impact of charging/discharging on the power grid, reliable communication and data exchange among electric vehicles, charging stations and distribution power system are needed. Based on the smart grid reference architecture [11] and the framework for cyber-physical system [12], we propose a four-layered architecture for energy trading in a smart parking lot, as shown in Figure 1. The proposed architecture consists of a parking energy layer, a data acquisition layer, a communication network layer, and a market layer.

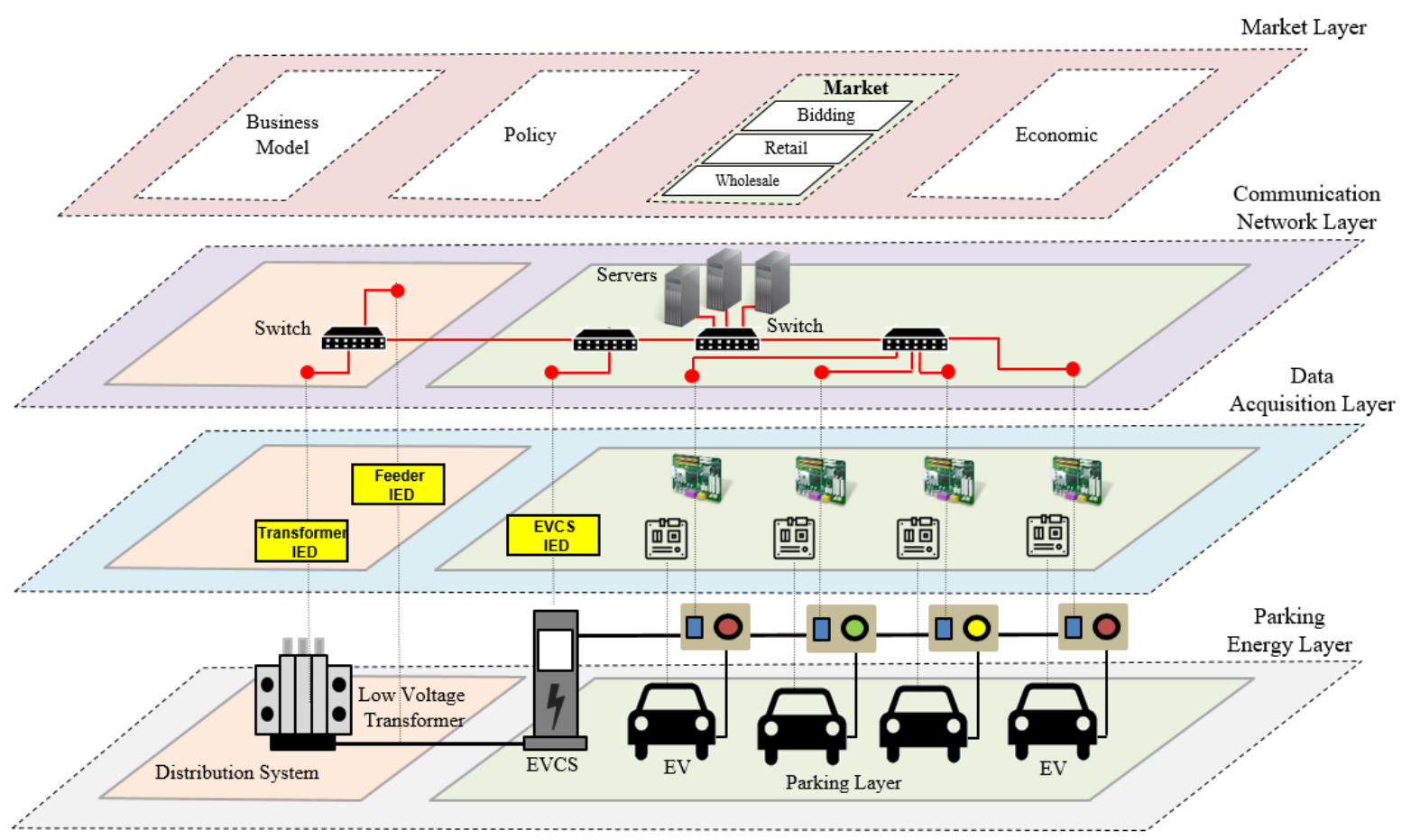

Figure 1. Proposed system architecture for energy trading in smart parking lots. EV: electric vehicle; EVCS: electric vehicle charging station; IED: intelligent electronic device.

\subsection{Parking Energy Layer}

The parking energy layer includes the distribution power system, transformers, feeders, and charging stations. The distribution power system delivers electric power to charging stations at parking 
lots in residential, commercial, and industrial areas. Electric vehicles are connected to the distribution power system to charge/discharge their batteries through charging stations. There are three basic types of charging stations: slow charging, moderate charging, and fast charging.

\subsection{Data Acquistion Layer}

The data acquisition layer is responsible for collecting data from different electric vehicle subsystem through sensor nodes and monitoring devices. Based on the application requirement, slow / fast data acquisition modules are used. Taken the electric vehicle battery as an example, there are a variety of sensor nodes that are used for monitoring the battery status, such as voltage, current, and temperature.

\subsection{Communication Network Layer}

Information and communication technologies aim to support and manage the energy transfer between electric vehicles and the power grid. The communication network layer enables real-time data exchange between different components in the electric vehicle system. The communication infrastructure consists of communication devices, wired/wireless communication connections, routers, switches, servers, etc.

\subsection{Market Layer}

The market Layer represents the business view of the smart parking lot. It consists of two parts: the wholesale market and the retail market. The main participants in the market domain are selling vehicles, buying vehicles, the parking lot operator (PLO) and the distribution system operator (DSO). The main processes of the market layer include bidding, decision, energy exchange, and settlement.

\section{Proposed Market Mechanism}

There are two main parts that are needed in order to enable energy trading in a smart parking lot: a physical energy network and a virtual energy market platform [13]. The physical energy network is required for energy transfer among electric vehicles and the parking lot operator, while the virtual energy market platform is needed to enable a local energy market for energy selling and buying. Communication networks are used to exchange information among different components of the smart parking lot. Figure 2 shows an overview of the proposed energy trading system in a smart parking lot. The main components are input data, collecting bids, auction, declare and notification, energy exchange, and settlement.

We assume that each charging station is capable of collecting information regarding the vehicles' arrival time, departure time, and participation in the energy trading market. The parking lot control center monitors the status of all charging stations and coordinates the charging (parking lot-to-vehicles (PL2V)) and discharging (vehicles-to-parking lot (V2PL)) operations of each station. Different wired/wireless communication technologies could be used for communication between the parking lot control center (PLCC) and charging stations. Table 1 shows an overview of the proposed energy trading in a smart parking lot.

Table 1. Overview of proposed smart parking lot characteristics.

\begin{tabular}{cc}
\hline & Characteristic \\
\hline Smart Parking Lot & PL2V and V2PL \\
Energy Trading Objective & Profit maximization for PLCC \\
Scale & Single parking lot, multiple parking lots \\
Control Type & Centralized solution, decentralized solution \\
Price Model & Time of use (TOU), real-time price (RTP) \\
\hline C: parking lot control center; PL2V: Parking Lot-to-Vehicles; V2PL: Vehicles-to-Parking Lot
\end{tabular}




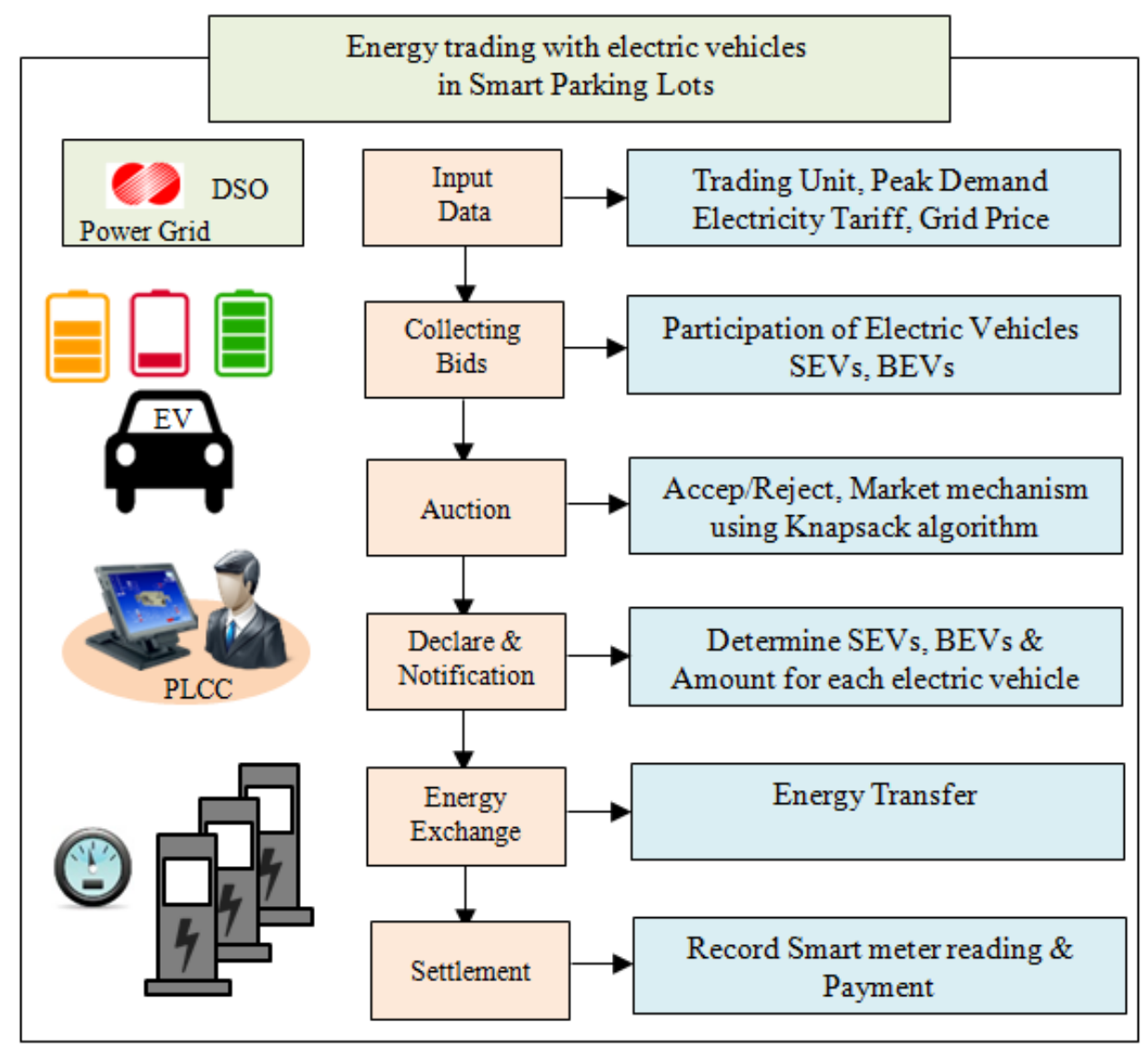

Figure 2. Overview of the proposed energy trading system in a smart parking lot. SEV: seller electric vehicle; BEV: buyer electric vehicle; DSO: distribution system operator; PLCC: parking lot control center.

Figure 3 shows the system model of a smart parking lot. The PLCC is responsible for managing the charging of parked electric vehicles based on their status data (arrival time, departure time, state of charge (SOC)). We classified electric vehicles into three different types: seller electric vehicles (SEVs) with an excess of energy in the battery, buyer electric vehicles (BEVs) with lack of energy in the battery, and idle electric vehicles (IEVs).

- Seller electric vehicles (SEVs) denoted SEVi, i =1,2, .., N. SEVs have extra power and represent energy providers.

- Buyer electric vehicles (BEVs) denoted $B E V j, j=1,2, \ldots, K$. BEVs demand power for charging and represent energy consumers.

- Idle electric vehicles (IEVs) do not participate in any energy trading activities.

In this work, the market mechanism for the smart parking lot was implemented based on the Knapsack Algorithm (KPA) [14] and deployed in the PLCC. The main objective of the PLCC is to coordinate the energy trading among SEVs, BEVs, and PLCC. Each SEV can submit an energy request $R_{\mathrm{SEVi}}$ for selling energy at time $t$. $\mathrm{R}_{\mathrm{SEVi}}$ is represented by $\left(\mathrm{SEV}_{\mathrm{ID}}, \mathrm{SEV}_{\mathrm{SA}}, \mathrm{SEV}_{\mathrm{SP}}\right)$ where $\mathrm{SEV}_{\mathrm{ID}}, \mathrm{SEV}_{\mathrm{SA}}$, $\mathrm{SEV}_{\mathrm{SP}}$ are the vehicle identification, the amount of energy to be exchanged, and the suggested price of energy, respectively. Also, BEVs request the amount of energy for charging from the PLCC. Each BEV can submit an energy demand request $\left(\mathrm{R}_{\mathrm{BEV}}\right)$ at time t. $\mathrm{R}_{\mathrm{BEV}}$ is represented by $\left(\mathrm{BEV}_{\mathrm{ID}}, \mathrm{BEV}_{\mathrm{BA}}, \mathrm{BEV}_{\mathrm{BP}}\right)$ where $\mathrm{BEV}_{\mathrm{ID}}, \mathrm{BEV}_{\mathrm{BA}}, \mathrm{BEV}_{\mathrm{BP}}$ are the vehicle identification, the amount of demand energy for charging, and the offered price of energy, respectively. The PLCC gathers all offer/demand requests and selects a set of electric vehicles to trade with. The main objective of PLCC is to maximize the total profit as 
given in Equation (1). The PLCC aims to maximize energy selling to charging vehicles and minimize purchasing/buying energy from discharging vehicles while respecting vehicles' requirements.

$$
\text { Maximize PROFIT } P L C C \sum_{t=1}^{T} \sum_{i=1}^{N} \sum_{j=1}^{K}\left(B A_{j}^{t} \times B P_{j}^{t} \times x_{j}^{t}-S A_{i}^{t} \times S P_{i}^{t} \times x_{i}^{t}\right)
$$

$\begin{array}{cl}\text { where } & \\ B A_{j}^{t} & \text { Buying amount of energy by } \mathrm{BEV}_{\mathrm{j}} \text { at time } \mathrm{t} \\ B P_{j}^{t} & \text { Buying price by } \mathrm{BEV}_{\mathrm{j}} \text { at time } \mathrm{t} \\ x_{j}^{t} & \text { Allocation index for } \mathrm{BEV}_{\mathrm{j}} \text { at time } \mathrm{t} \\ S A_{i}^{t} & \text { Selling amount of energy by } \mathrm{SEV}_{\mathrm{i}} \text { at time } \mathrm{t} \\ S P_{i}^{t} & \text { Selling price by } \mathrm{SEV}_{\mathrm{i}} \text { at time } \mathrm{t} \\ x_{i}^{t} & \text { Allocation index for } \mathrm{SEV}_{\mathrm{i}} \text { at time } \mathrm{t} \\ T & \text { Number of auction time interval } \\ N & \text { Number of SEVs } \\ K & \text { Number of BEVs }\end{array}$

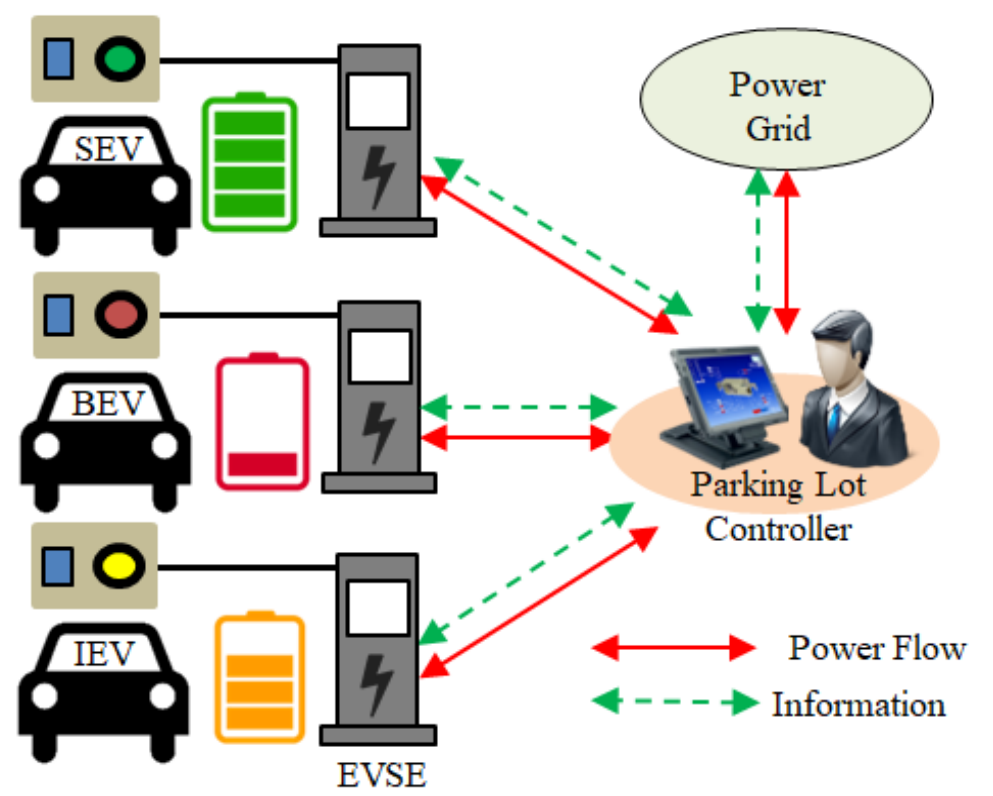

Figure 3. System model for energy trading in a smart parking lot.

The main objective of PLCC is to maximize its profits (PROFIT $\left.T_{P L C C}\right)$ by selling/buying energy to/from electric vehicles as well as the power grid, as given in Equation (2).

$$
\text { PROFIT }_{P L C C}=\sum_{t=0}^{T}\left(\text { Revenue } P L C C, t-\operatorname{COST}_{P L C C, t}\right)
$$

where

Revenue $P$ LCC,t Total revenue earned by PLCC

COST $_{P L C C, t}$ Total cost paid by the PLCC

$T \quad$ Number of scheduling intervals per day

The total revenue of PLCC (Revenue $P_{L C C, t}$ ) includes selling energy to the grid as well as selling energy for charging EVs, as given in Equation (3).

$$
\text { Revenue }_{P L C C, t}=\text { Revenue }_{S T G, t}+\text { Revenue }_{S T V, t}
$$




$$
\begin{gathered}
\text { Revenue }_{S T G, t}=P_{S T G, t} \times p_{S T G, t} \times \Delta t \\
\text { Revenue }_{S T V, t}=\Delta t \times \sum_{i=1}^{K} P_{S T V, i, t} \times p_{S T V, i, t}
\end{gathered}
$$

where

Revenue $_{S T G, t}$ Revenue earned by providing power from SEVs to the grid (selling to grid)

Revenue $_{S T V, t}$ Revenue earned by supporting power to charging BEVs (selling to BEVs)

$P_{S T G, t} \quad$ Power sold to the grid in $\mathrm{kW}$

$p_{S T G, t} \quad$ Electricity price in money unit per $\mathrm{kWh}$

$\Delta t \quad$ Length of scheduling interval

K Number of BEVs

$P_{S T V, i, t} \quad$ Power used to charge $\mathrm{BEV}_{\mathrm{i}}$ in $\mathrm{kW}$

$p_{S T V, i, t} \quad$ Electricity price in money unit per $\mathrm{kWh}$

The total cost of PLCC $\left(C O S T_{P L C C, t}\right)$ includes buying energy from the grid as well as buying energy from SEVs, as given in Equation (6).

$$
\begin{gathered}
\operatorname{COST}_{P L C C, t}=\operatorname{COST}_{B F G, t}+\operatorname{COST}_{B F V, t} \\
\operatorname{COST}_{B F G, t}=P_{B F G, t} \times p_{B F G, t} \times \Delta t \\
\operatorname{COST}_{B F V, t}=\Delta t \times \sum_{i=1}^{N} P_{B F V, i, t} \times p_{B F V, i, t}
\end{gathered}
$$

where

COST $_{B F G, t} \quad$ Cost of energy purchased from the grid

$\operatorname{COST}_{B F V, t} \quad$ Cost of energy purchased from SEVs

$P_{B F G, t} \quad$ Power bought from the grid in $\mathrm{kW}$

$p_{B F G, t} \quad$ Electricity price in money units per $\mathrm{kWh}$

$\Delta t \quad$ Length of scheduling interval

$N \quad$ Number of SEVs

$P_{B F V, i} \quad$ Discharge power from $\mathrm{SEV}_{\mathrm{i}}$ in $\mathrm{kW}$

$p_{B F V, i} \quad$ Electricity price in money unit per $\mathrm{kWh}$

\section{Simulation Results}

This section evaluates the performance of the proposed market mechanism for campus parking lots at Chonbuk National University, Jeonju Campus, South Korea. The market mechanism was evaluated from the PLCC perspective. There are 8 parking lots distributed around the campus (CBNU-PL1 CBNU-PL8), as shown in Figure 4.

\subsection{Electric Vehicle Model}

Real data for vehicles' arrivals and departures were collected on a weekday (Tuesday 15 May 2018) from 6:00 a.m. until 18:30 p.m. at the parking lot of engineering building 2-7 (CBNU-PL3), as shown in Figure 5. CBNU-PL3 serves faculty members, employees, and students. The arrival and departure times were based on working hours and student class schedules.

Different brands for electric vehicles in South Korea were considered based on Ref. [15]. The specifications of electric vehicles are given in Table 2. The amount of selling/buying energy of each vehicle was considered to be 50 percentage of the battery capacity. 


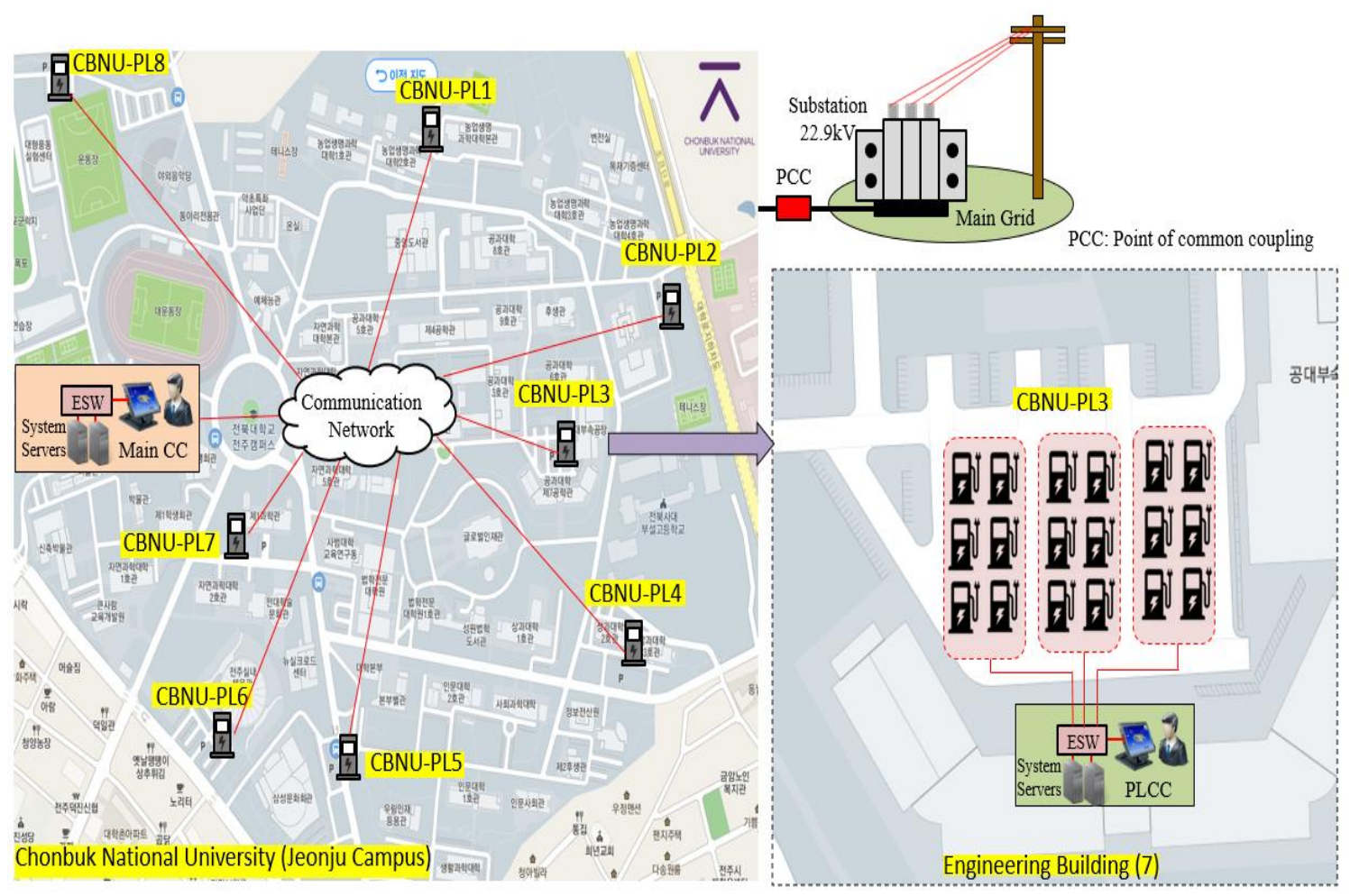

Figure 4. Campus parking lots at Chonbuk National University, Jeonju Campus, South Korea.

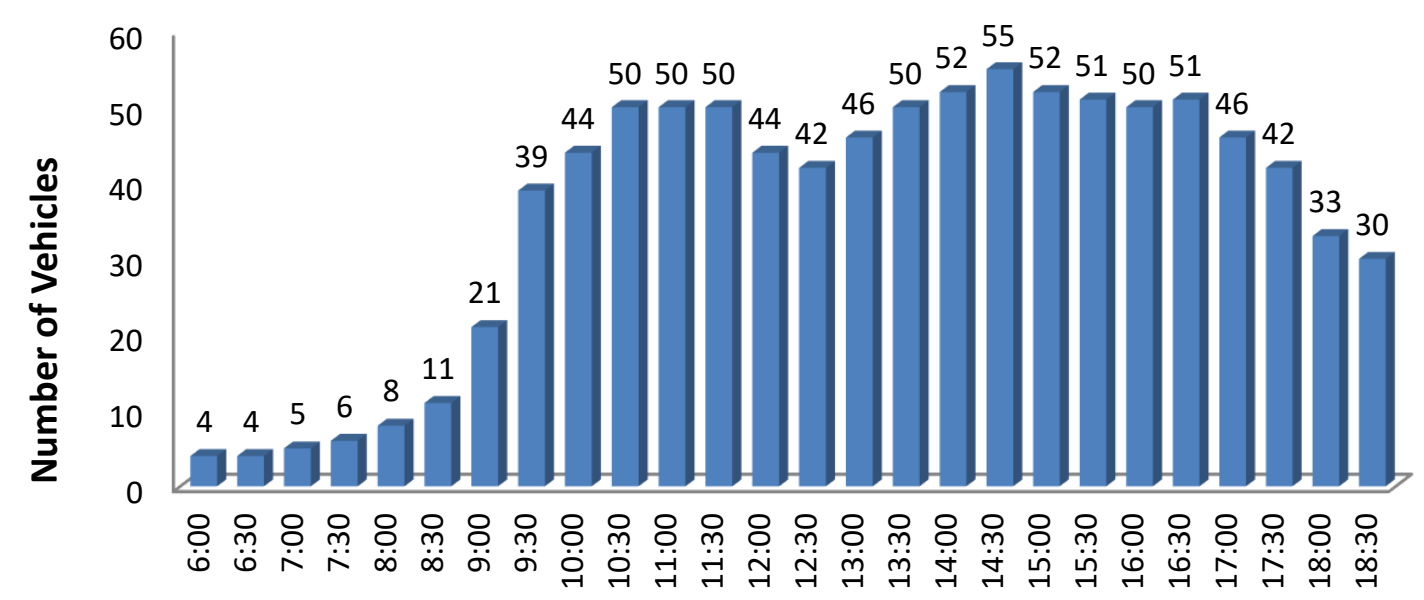

Time

Figure 5. Typical parking utilization during weekdays (CBNU-PL3), 15 May 2018.

Table 2. Electric vehicle specification.

\begin{tabular}{cccc}
\hline Vehicle Model & Battery Capacity & Fuel Economy $\mathbf{( K m} / \mathbf{k W h})$ & Release Year \\
\hline SOUL & $27 \mathrm{kWh}$ & 5.0 & 2014 \\
LEAF & $24 \mathrm{kWh}$ & 5.2 & 2014 \\
SM3 Z.E. & $22 \mathrm{kWh}$ & 4.4 & 2013 \\
BMW i3 & $18 \mathrm{kWh}$ & 5.9 & 2014 \\
RAY & $16 \mathrm{kWh}$ & 5.0 & 2012 \\
\hline
\end{tabular}

Table 3 shows the electric vehicle charging tariff by KEPCO. The electric vehicle charging tariff is different based on the time period (off-peak, mid-peak and on-peak) and the season (summer, spring, 
fall and winter) [14]. We assumed that selling/buying prices were randomly selected based on KEPCO electric vehicle charging tariff in the range of $[50,200] \mathrm{KRW}$.

Table 3. Electric vehicle charging tariff [16].

\begin{tabular}{ccccc}
\hline \multirow{2}{*}{ Time } & \multirow{2}{*}{ Classification } & \multicolumn{3}{c}{ Energy Charge (KRW/kWh) } \\
\cline { 3 - 5 } & & Summer & Spring/Fall & Winter \\
\hline Off-Peak & & 57.6 & 58.7 & 80.7 \\
Mid-Peak & Low voltage & 145.3 & 70.5 & 128.2 \\
On-Peak & & 232.5 & 75.4 & 190.8 \\
\hline
\end{tabular}

Different scenarios were considered for energy trading with respect to the load profile of engineering building 2-7 shown in Figure 6, and the minimum and maximum power consumption given in Table 4. These scenarios were as follows: (a) Scenario (1)-a standalone parking lot with 10 charging stations and energy trading of $50 \mathrm{kWh}$, (b) Scenario (2) - two parking lots with 20 charging stations and energy trading of $100 \mathrm{kWh}$, (c) Scenario (3) - four parking lots with 40 charging stations and energy trading of $200 \mathrm{kWh}$, and (d) Scenario (4) - eight parking lots with 80 charging stations and energy trading of $400 \mathrm{kWh}$. Table 5 shows a list of the simulation scenarios. We assumed that the excess energy from electric vehicles could support the peak demand of university buildings. The feeding of excess power from electric vehicles to the grid was not considered in this work.

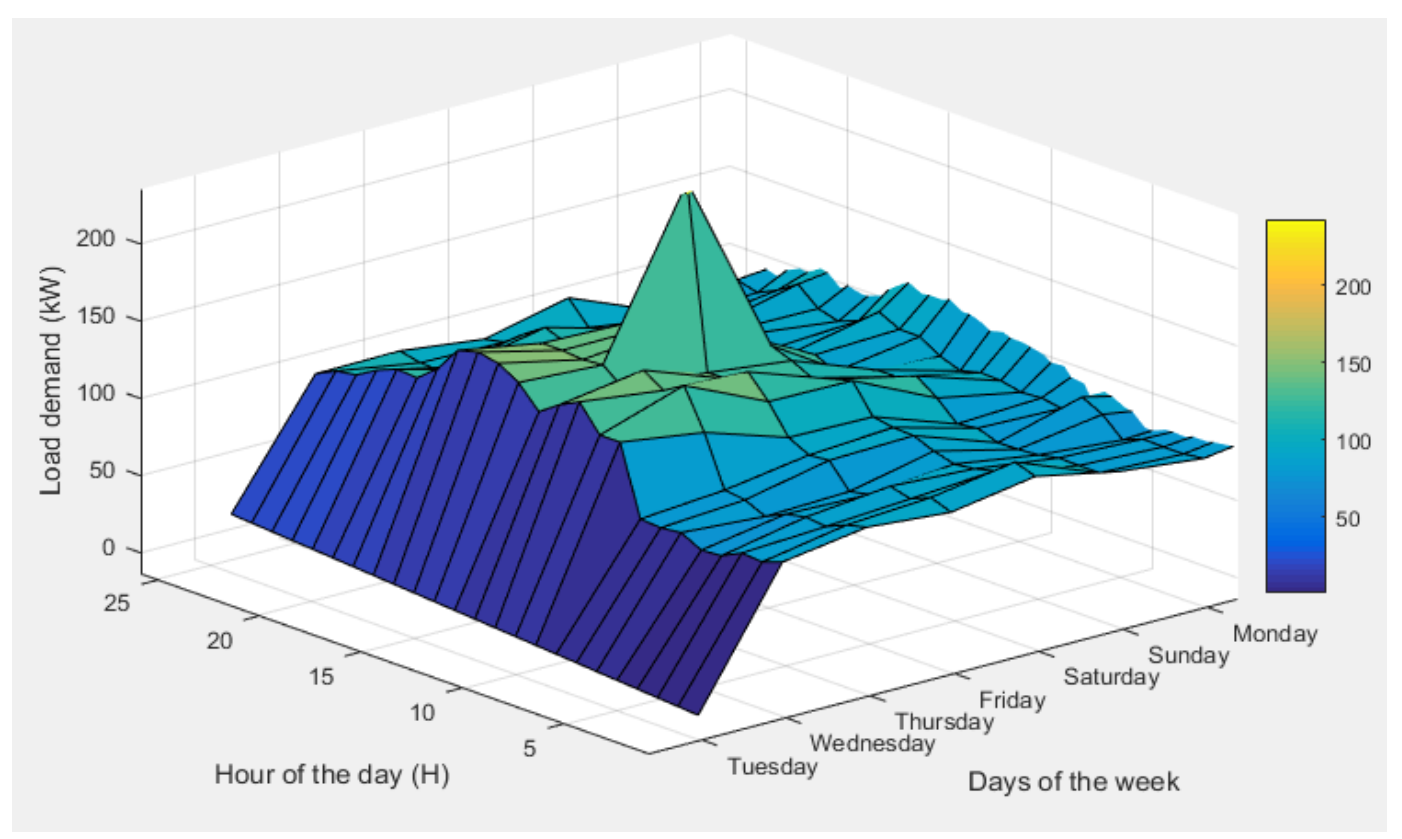

Figure 6. Load profile of engineering building 2-7 from 8 May 2018 to 14 May 2018.

Table 4. Power consumption of engineering building 2-7 (8 May 2018 14 May 2018).

\begin{tabular}{ccc}
\hline \multirow{2}{*}{ Day } & \multicolumn{2}{c}{ Power Consumption (kW) } \\
\cline { 2 - 3 } & Min & Max \\
\hline Tuesday & 75 & 152 \\
Wednesday & 77.8 & 144.6 \\
Thursday & 79.7 & 243 \\
Friday & 72.6 & 131.1 \\
Saturday & 78 & 102.5 \\
Sunday & 74.7 & 101.8 \\
Monday & 77.8 & 150.5 \\
\hline
\end{tabular}


Table 5. Simulation scenarios.

\begin{tabular}{cccc}
\hline & Number of Parking Lots & Case & Demand \\
\hline Scenario (1) & $\begin{array}{c}\text { Single PL } \\
\text { 10 Charging Stations }\end{array}$ & $\begin{array}{c}\text { Case (1): SEVs } \\
\text { Case (2): BEVs }\end{array}$ & $50 \mathrm{kWh}$ \\
\hline Scenario (2) & $\begin{array}{c}\text { 2-PLs } \\
\text { 20 Charging Stations }\end{array}$ & $\begin{array}{c}\text { Case (3): SEVs } \\
\text { Case (4): BEVs }\end{array}$ & $100 \mathrm{kWh}$ \\
\hline Scenario (3) & $\begin{array}{c}\text { 4-PLs } \\
\text { 40 Charging Stations }\end{array}$ & $\begin{array}{c}\text { Case (5): SEVs } \\
\text { Case (6): BEVs }\end{array}$ & $200 \mathrm{kWh}$ \\
\hline Scenario (4) & $\begin{array}{c}\text { 8-PLs } \\
\text { 80 Charging Stations }\end{array}$ & $\begin{array}{c}\text { Case (7): SEVs } \\
\text { Case (8): BEVs }\end{array}$ & $400 \mathrm{kWh}$ \\
\hline
\end{tabular}

\subsection{Standalone Parking Lot: Electric Vehicles as Sellers and the PLCC as a Buyer}

All vehicles in case (1) were considered to be selling vehicles. The energy bought from SEVs could be used to support the load demand of engineering building 2-7 or used to charge other electric vehicles. Considering a local demand of $50 \mathrm{kWh}$, the PLCC selected a set of electric vehicles to satisfy the local demand, as given in Algorithm 1. Tables 6 and 7 compare the proposed energy trading mechanism using the Knapsack Algorithm (KPA) with the first-come-first-serve (FCFS) scheme. In the FCFS scheme, the PLCC selects electric vehicles that request selling first. In KPA, the PLCC sorts the revenue in an ascending order in order to minimize the cost of buying energy from SEVs. The PLCC selects a set of electric vehicles with lower selling prices to trade with. The simulation results of Figure 7 show that the proposed energy trading mechanism based on KPA outperforms the FCFS scheme with a reduction in costs of about $47 \%$. For a single parking lot with 10 electric vehicles as sellers, the average parking lot costs would be about $4334 \mathrm{KRW}$ and $2508 \mathrm{KRW}$ for FCFS and KPA, respectively.

Table 6. Case (1) with the first-come-first-serve (FCFS) scheme for electric vehicles as sellers and the PLCC as a buyer.

\begin{tabular}{|c|c|c|c|c|c|c|c|}
\hline & \multicolumn{3}{|c|}{ Seller Vehicles } & \multicolumn{4}{|c|}{ FCFS } \\
\hline & $\begin{array}{l}\text { Amount } \\
(\mathrm{kWh})\end{array}$ & $\begin{array}{c}\text { Price } \\
\text { (KRW/kWh) }\end{array}$ & $x_{i}^{t}$ & $\begin{array}{c}\text { Amount } \\
(\mathrm{kWh})\end{array}$ & $\begin{array}{l}\text { EV's Revenue } \\
\text { (KRW) }\end{array}$ & $\begin{array}{c}\text { OPEX } \\
\text { KRW/kWh }\end{array}$ & $\begin{array}{c}\operatorname{COST}_{\text {PLCC }} \\
\text { Seller Profit } \\
\text { (KRW) }\end{array}$ \\
\hline SEV1 & 12 & 81 & 1 & 12 & 972 & 516 & 456 \\
\hline SEV2 & 12 & 60 & 1 & 12 & 720 & 516 & 204 \\
\hline SEV3 & 9 & 171 & 1 & 9 & 1539 & 387 & 1152 \\
\hline SEV4 & 8 & 146 & 1 & 8 & 1168 & 344 & 824 \\
\hline SEV5 & 11 & 189 & 0.81 & 9 & 1701 & 387 & 1314 \\
\hline SEV6 & 9 & 59 & 0 & 0 & 0 & 0 & 0 \\
\hline SEV7 & 12 & 166 & 0 & 0 & 0 & 0 & 0 \\
\hline SEV8 & 13.5 & 190 & 0 & 0 & 0 & 0 & 0 \\
\hline SEV9 & 8 & 85 & 0 & 0 & 0 & 0 & 0 \\
\hline SEV10 & 12 & 193 & 0 & 0 & 0 & 0 & 0 \\
\hline Total & 106.5 & & & 50 & 6100 & 2150 & 3950 \\
\hline
\end{tabular}

Table 7. Case (1) with the Knapsack Algorithm (KPA) scheme for electric vehicles as sellers and the PLCC as a buyer.

\begin{tabular}{cccccccc}
\hline & \multicolumn{2}{c}{ Seller Vehicles } & \multicolumn{4}{c}{ Proposed KPA } \\
\cline { 2 - 7 } & $\begin{array}{c}\text { Amount } \\
\mathbf{( k W h )}\end{array}$ & $\begin{array}{c}\text { Price } \\
(\text { KRW/kWh) }\end{array}$ & $\boldsymbol{x}_{\boldsymbol{i}}^{t}$ & $\begin{array}{c}\text { Amount } \\
\mathbf{( k W h )}\end{array}$ & $\begin{array}{c}\text { EVs } \\
\text { Revenue } \\
\text { (KRW) }\end{array}$ & $\begin{array}{c}\text { OPEX } \\
\text { KRW/kWh }\end{array}$ & $\begin{array}{c}\text { COST } \\
\text { Seller Profit } \\
\text { (KRW) }\end{array}$ \\
\hline SEV6 & 9 & 59 & 1 & 9 & 531 & 387 & 144 \\
SEV2 & 12 & 60 & 1 & 12 & 720 & 516 & 204 \\
SEV9 & 8 & 85 & 1 & 8 & 680 & 344 & 336 \\
SEV1 & 12 & 81 & 1 & 12 & 972 & 516 & 456 \\
SEV4 & 8 & 146 & 1 & 8 & 1168 & 344 & 824 \\
\hline
\end{tabular}


Table 7. Cont.

\begin{tabular}{cccccccc}
\hline & \multicolumn{2}{c}{ Seller Vehicles } & \multicolumn{4}{c}{ Proposed KPA } \\
\cline { 2 - 7 } & $\begin{array}{c}\text { Amount } \\
\mathbf{( k W h )}\end{array}$ & $\begin{array}{c}\text { Price } \\
(\text { KRW/kWh })\end{array}$ & $\boldsymbol{x}_{\boldsymbol{i}}^{t}$ & $\begin{array}{c}\text { Amount } \\
\mathbf{( k W h )}\end{array}$ & $\begin{array}{c}\text { EVs } \\
\text { Revenue } \\
(\text { KRW) }\end{array}$ & $\begin{array}{c}\text { OPEX } \\
\text { KRW/kWh }\end{array}$ & $\begin{array}{c}\text { COST } \\
\text { Seller Profit } \\
\text { (KRW) }\end{array}$ \\
\hline SEV3 & 9 & 171 & 0.11 & 1 & 171 & 43 & 128 \\
SEV7 & 12 & 166 & 0 & 0 & 0 & 0 & 0 \\
SEV5 & 11 & 189 & 0 & 0 & 0 & 0 & 0 \\
SEV10 & 12 & 193 & 0 & 0 & 0 & 0 & 0 \\
SEV8 & 13.5 & 190 & 0 & 0 & 0 & 0 & 0 \\
\hline Total & 106.5 & & & 50 & 4242 & 2150 & 2092 \\
\hline
\end{tabular}

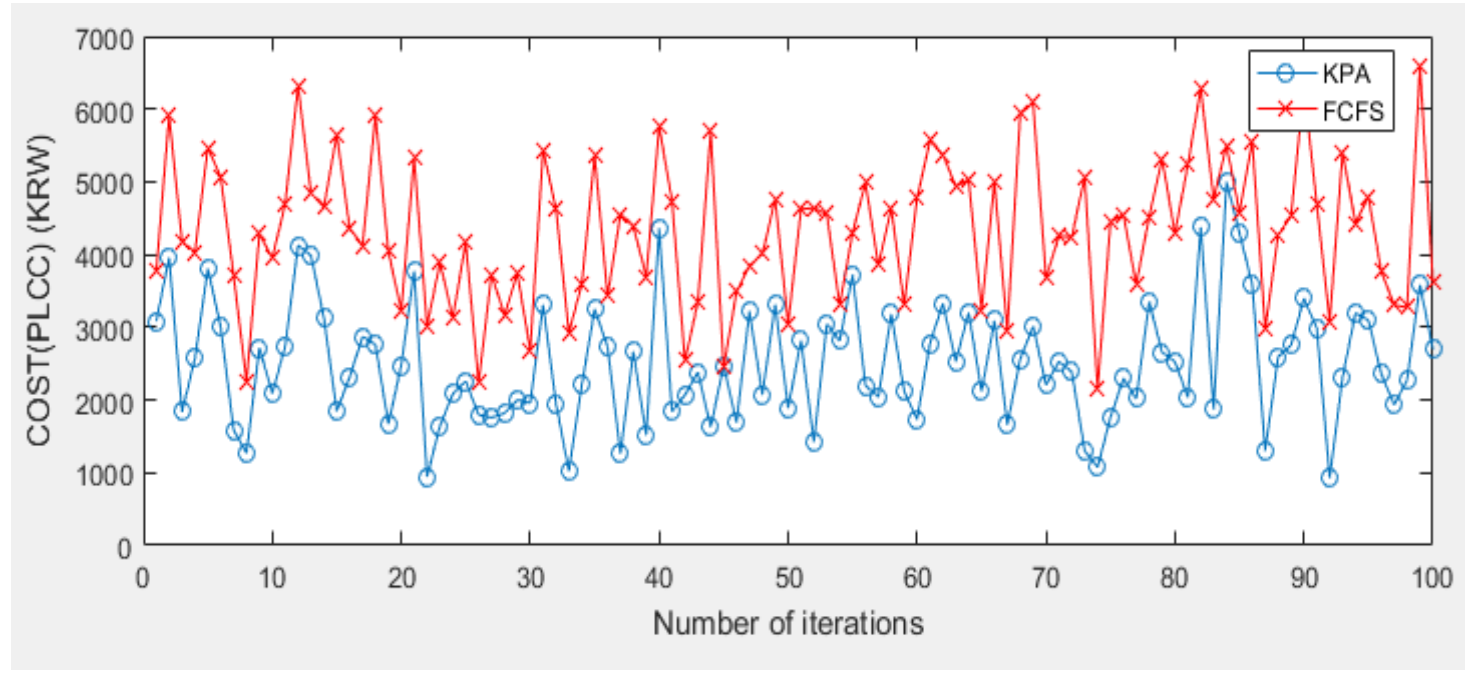

Figure 7. Results of the total COST for PLCC in Case (1): demand $50 \mathrm{~kW}, 10 \mathrm{EVs}$.

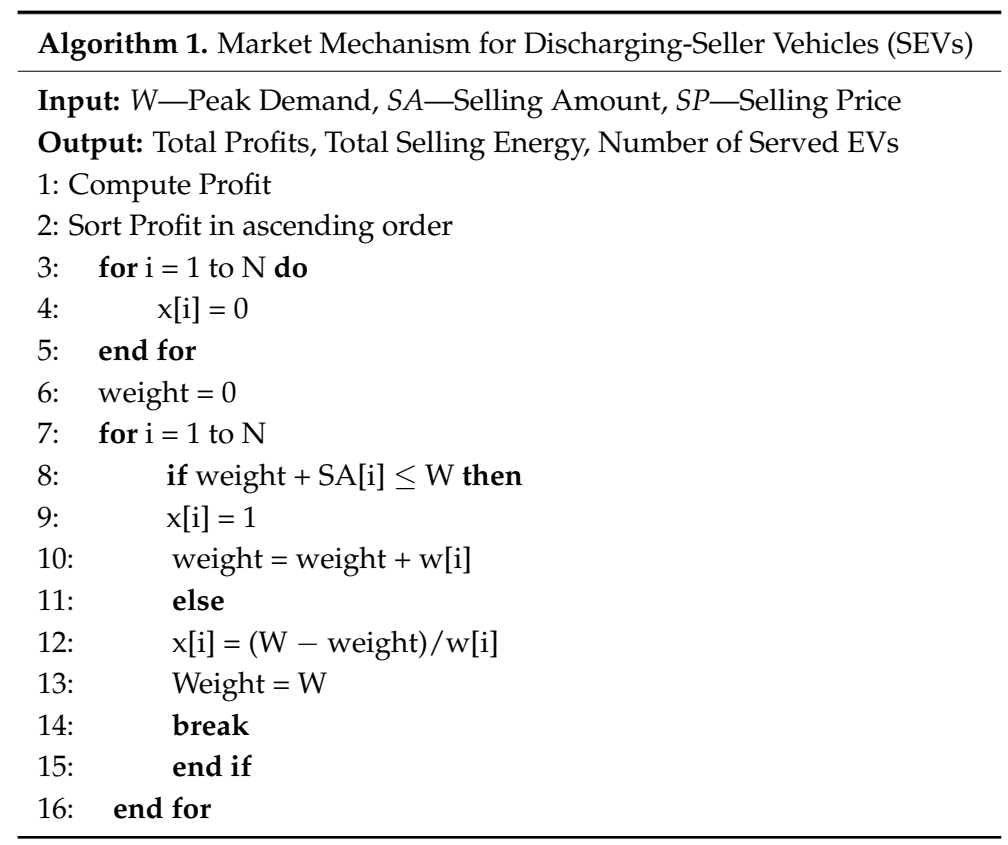

\subsection{Standalone Parking Lot: Electric Vehicles as Buyers and the PLCC as a Seller}

All vehicles in Case (2) were considered to be buying vehicles. Each vehicle requests the amount of buying energy that is required for charging and the buying price that vehicle owner is willing to pay. In order to maximize the PLCC profit from buying vehicles, the PLCC sorts profit in a descending order, 
as shown in Algorithm 2. Tables 8 and 9 compare the proposed energy trading mechanism using KPA with the FCFS scheme. In KPA, the PLCC selects a set of electric vehicles with higher buying prices to trade with. Figure 8 compares the total profits of the proposed energy trading mechanism based on the KPA and FCFS schemes. The proposed energy trading mechanism based on KPA outperforming the FCFS scheme with a profit increase of about $44 \%$. For a single parking lot with 10 electric vehicles as buyers, the average parking lot profits would be about 4334 KRW and 5964 KRW for FCFS and KPA, respectively.

Table 8. Case (2) with FCFS for electric vehicles as buyers and the PLCC as a seller.

\begin{tabular}{cccccccc}
\hline & \multicolumn{2}{c}{ Buyer Vehicles } & & & \multicolumn{3}{c}{ FCFS } \\
\cline { 2 - 8 } & $\begin{array}{c}\text { Amount } \\
\mathbf{( k W h )}\end{array}$ & $\begin{array}{c}\text { Price } \\
(\text { KRW/kWh) }\end{array}$ & $\boldsymbol{x}_{\boldsymbol{j}}^{t}$ & $\begin{array}{c}\text { Amount } \\
\mathbf{( k W h )}\end{array}$ & $\begin{array}{c}\text { Revenue } \\
\mathbf{( K R W )}\end{array}$ & $\begin{array}{c}\text { OPEX } \\
\text { KRW/kWh }\end{array}$ & $\begin{array}{c}\text { PLCC Profit } \\
\text { (KRW) }\end{array}$ \\
\hline BEV1 & 12 & 81 & 1 & 12 & 972 & 516 & 456 \\
BEV2 & 12 & 60 & 1 & 12 & 720 & 516 & 204 \\
BEV3 & 9 & 171 & 1 & 9 & 1539 & 387 & 1152 \\
BEV4 & 8 & 146 & 1 & 8 & 1168 & 344 & 824 \\
BEV5 & 11 & 189 & 0.81 & 9 & 1701 & 387 & 1314 \\
BEV6 & 9 & 59 & 0 & 0 & 0 & 0 & 0 \\
BEV7 & 12 & 166 & 0 & 0 & 0 & 0 & 0 \\
BEV8 & 13.5 & 190 & 0 & 0 & 0 & 0 & 0 \\
BEV9 & 8 & 85 & 0 & 0 & 0 & 0 & 0 \\
BEV10 & 12 & 193 & 0 & 0 & 0 & 0 & 0 \\
\hline Total & 106.5 & & & 50 & 6100 & 2150 & 3950 \\
\hline
\end{tabular}

Table 9. Case (2) with KPA scheme for electric vehicles as buyers and the PLCC as a seller.

\begin{tabular}{cccccccc}
\hline & \multicolumn{2}{c}{ Buyer Vehicles } & \multicolumn{5}{c}{ Proposed FNS } \\
\cline { 2 - 7 } & $\begin{array}{c}\text { Amount } \\
\mathbf{( k W h )}\end{array}$ & $\begin{array}{c}\text { Price } \\
(\mathbf{K R W / k W h})\end{array}$ & $\boldsymbol{x}_{j}^{t}$ & $\begin{array}{c}\text { Amount } \\
\mathbf{( k W h )}\end{array}$ & $\begin{array}{c}\text { Revenue } \\
\mathbf{( K R W )}\end{array}$ & $\begin{array}{c}\text { OPEX } \\
\text { KRW/kWh }\end{array}$ & $\begin{array}{c}\text { PLCC Profit } \\
\text { (KRW) }\end{array}$ \\
\hline BEV8 & 13.5 & 190 & 1 & 13.5 & 2565 & 580.5 & 1984 \\
BEV10 & 12 & 193 & 1 & 12 & 2316 & 516 & 1800 \\
BEV5 & 11 & 189 & 1 & 11 & 2079 & 473 & 1606 \\
BEV7 & 12 & 166 & 1 & 12 & 1992 & 516 & 1476 \\
BEV3 & 9 & 171 & 0.16 & 1.5 & 256 & 64.5 & 192 \\
BEV4 & 8 & 146 & 0 & 0 & 0 & 0 & 0 \\
BEV1 & 12 & 81 & 0 & 0 & 0 & 0 & 0 \\
BEV9 & 8 & 85 & 0 & 0 & 0 & 0 & 0 \\
BEV2 & 12 & 60 & 0 & 0 & 0 & 0 & 0 \\
BEV6 & 9 & 59 & 0 & 0 & 0 & 0 & 0 \\
\hline Total & 106.5 & & & 50 & 9208 & 2150 & 7058 \\
\hline
\end{tabular}

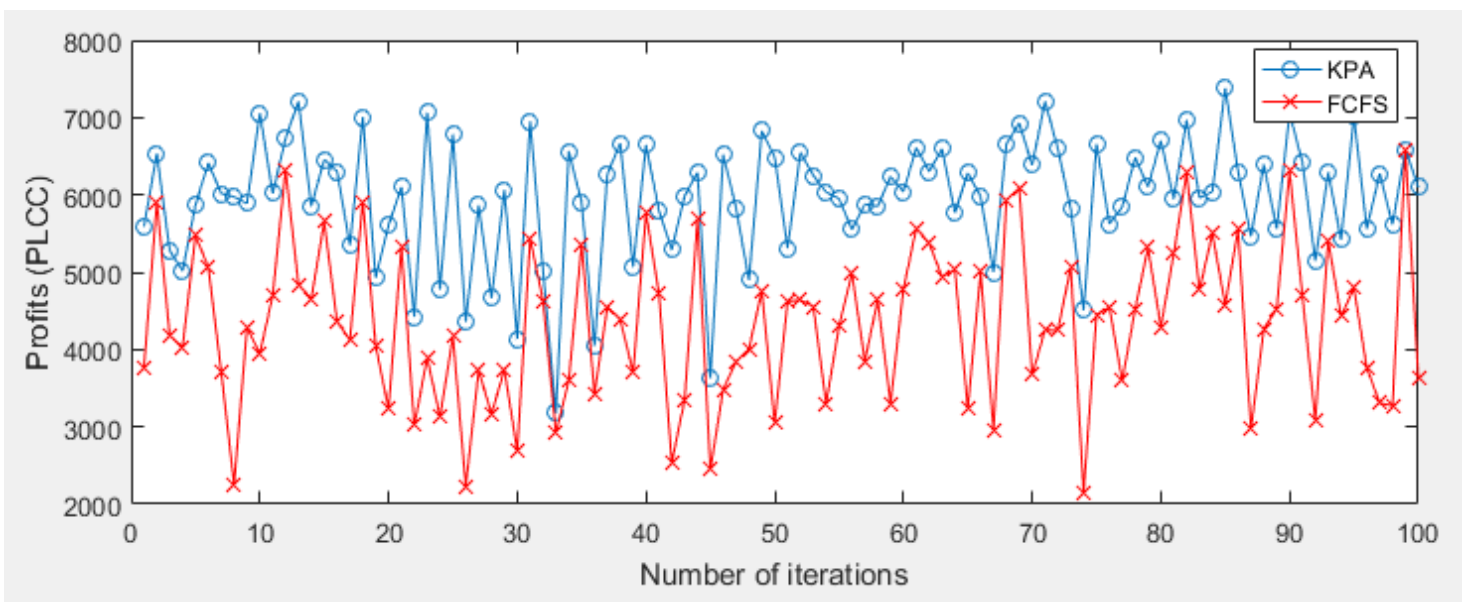

Figure 8. Results of total PROFIT for PLCC in Case (2): demand 50 kW, 10 EVs. 


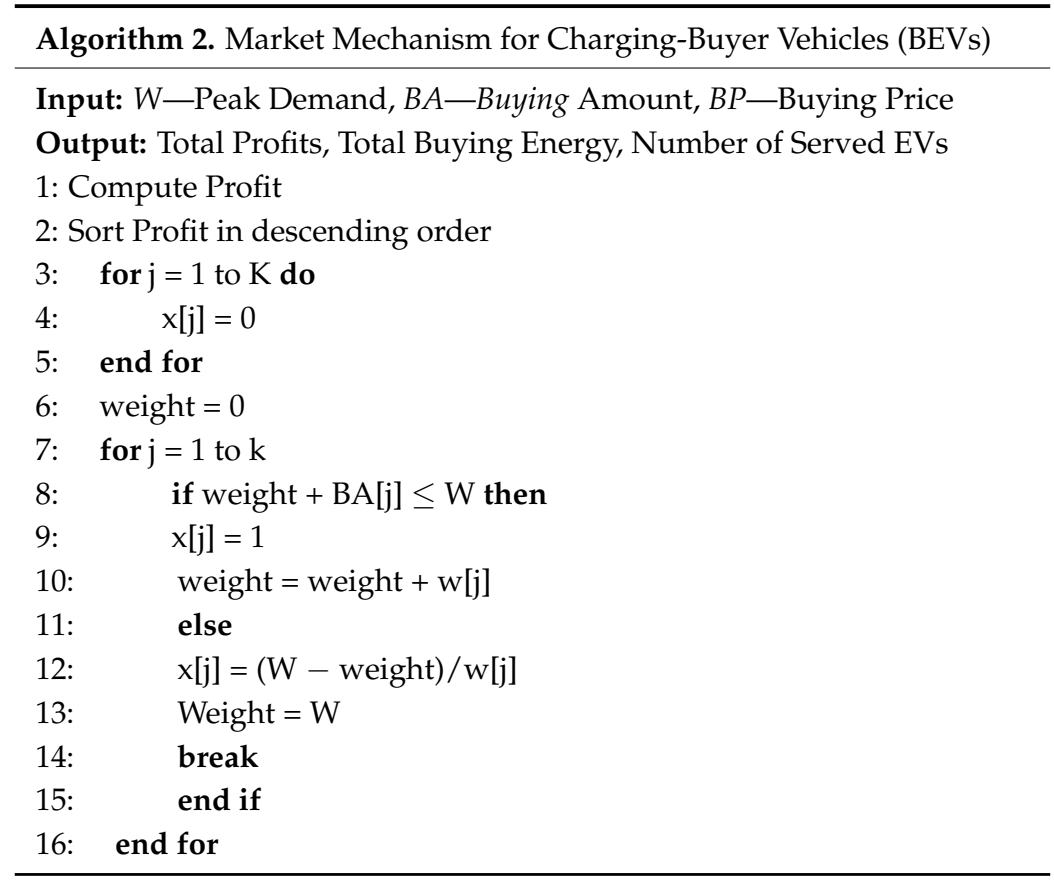

\subsection{Multiple Parking Lots}

We investigated the impact on costs and profits for multiple parking lots with respect to the number of electric vehicles and the amount of energy trading. Four scenarios were considered as given in Table 5. Figure 9 shows the average parking lot costs with different numbers of selling vehicles $(10,20,40$ and 80$)$ for the four considered scenarios. The results show that the market mechanism using KPA decreases the costs compared with the FCFS scheme. in Scenario 4, with 80 electric vehicles, the average parking lot costs are about 17,410 KRW with a cost reduction of about $46.6 \%$ compared with 32,622 KRW in the case of FCFS, as shown in Figure 10.

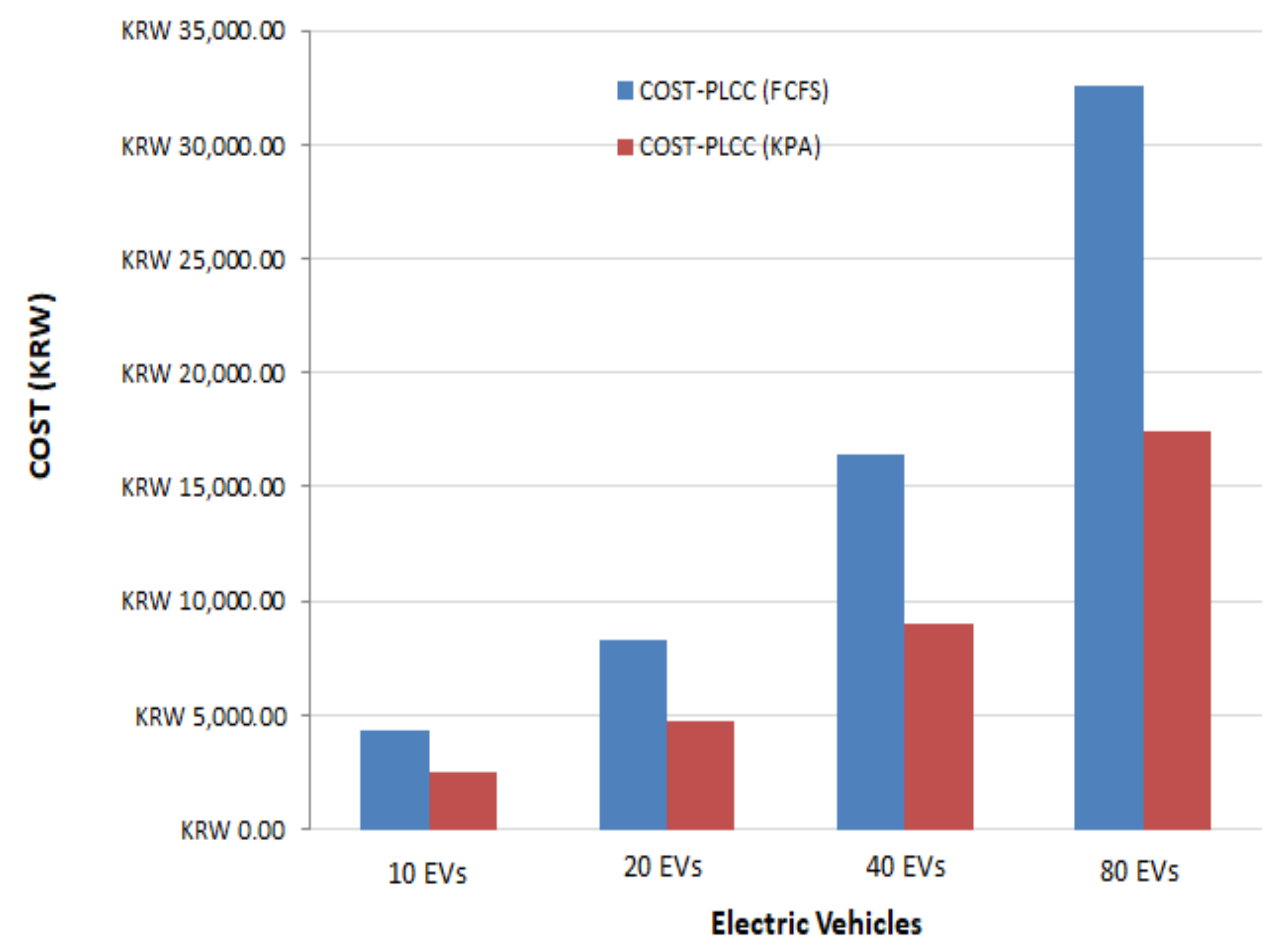

Figure 9. Average parking lot costs with different numbers of selling vehicles. 


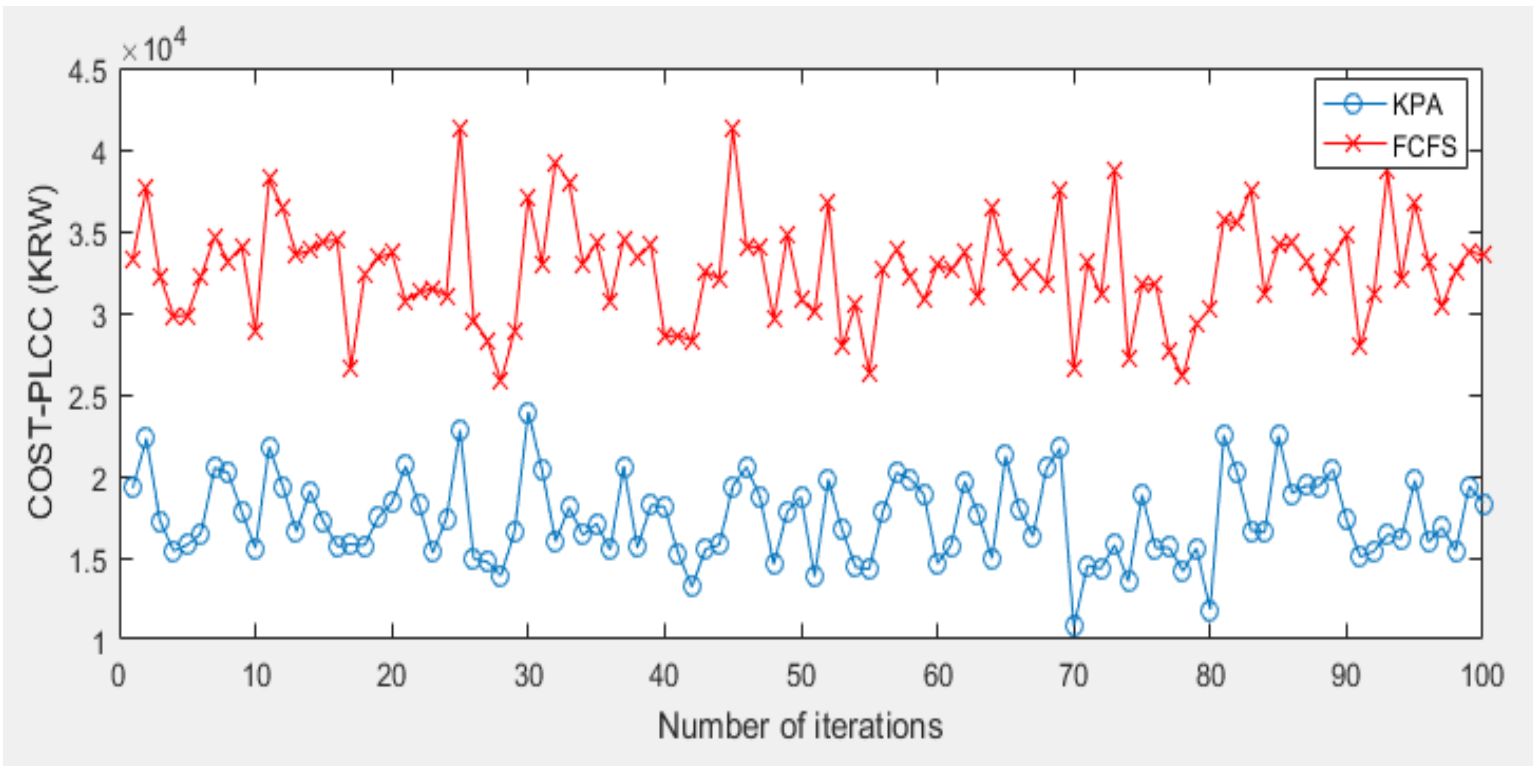

Figure 10. Results of total COST for the PLCC in Case (7): demand 400 kW, 80 EVs.

Figure 11 shows the average parking lot profits with different numbers of buying vehicles $(10,20$, 40 and 80). The market mechanism using KPA increases the profits compared with the FCFS scheme. The average parking lot profits are about $47,990 \mathrm{KRW}$ with a profit increase of about $32 \%$ compared with 32,622 KRW in the case of FCFS with 80 electric vehicles, as shown in Figure 12.

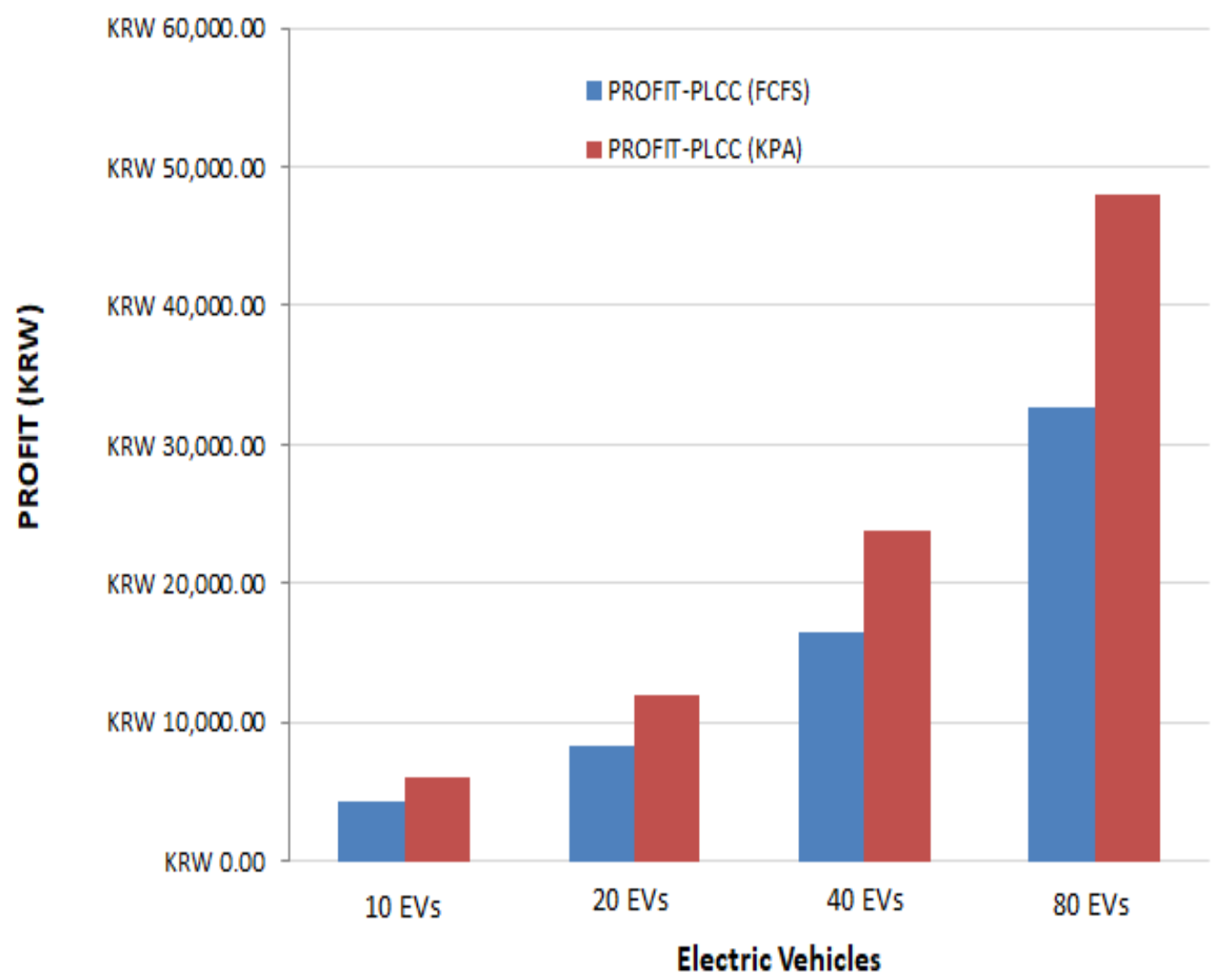

Figure 11. Average parking lot profits for different numbers of buying vehicles. 


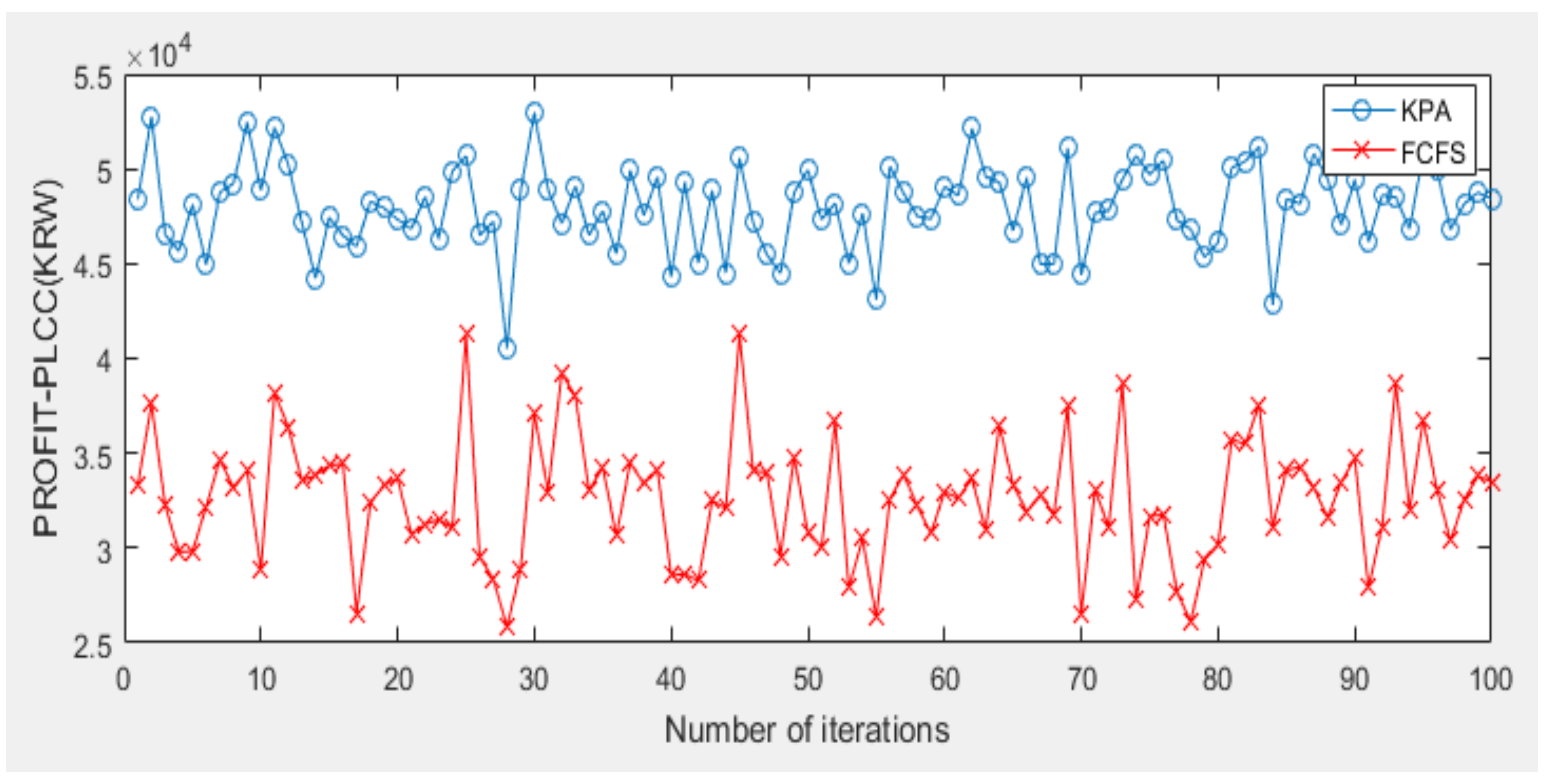

Figure 12. Results of total PROFIT for the PLCC in Case (8): demand $400 \mathrm{~kW}, 80 \mathrm{EVs}$.

\section{Conclusions}

We proposed a framework for energy trading in a smart parking lot. The proposed architecture consists of four layers: a parking energy layer, a data acquisition layer, a communication network layer, and a market layer. Electric vehicles were classified into three different types: seller vehicles, buyer vehicles, and idle vehicles. Based on the battery status, each vehicle decides its role for buying/selling energy from/to the PLCC. We developed a market mechanism for the PLCC based on the Knapsack Algorithm. We considered a real case study with a realistic parking pattern of a parking lot on a university campus. The simulation results showed that our proposed market mechanism can achieve better performance and cost saving for all participants including selling vehicles, buying vehicles, and the parking lot operator.

Author Contributions: Both authors contributed equally to this work.

Funding: This work was supported by research funds of Chonbuk National University in 2017 and the National Research Foundation of Korea (NRF) funded by the Ministry of Science, ICT and Future Planning (2017-004868).

Conflicts of Interest: The authors declare no conflict of interest.

\section{Nomenclature}

$\begin{array}{ll}\text { SEVs } & \text { Seller electric vehicles } \\ \text { BEVs } & \text { Buyer electric vehicles } \\ \text { IEVs } & \text { Idle electric vehicles } \\ \text { PLCC } & \text { Parking lot control center } \\ \text { KPA } & \text { Knapsack Algorithm } \\ \text { KEPCO } & \text { Korea Electric Power Corporation } \\ \text { RES } & \text { Renewable energy sources } \\ \text { ICT } & \text { Information and communication technologies } \\ \text { EV } & \text { Electric vehicle } \\ \text { EVCS } & \text { Electric vehicle charging station } \\ \text { IED } & \text { Intelligent electronic device } \\ \text { PLO } & \text { Parking lot operator } \\ \text { DSO } & \text { Distribution system operator } \\ \text { PL2V } & \text { Parking lot-to-vehicles } \\ \text { V2PL } & \text { Vehicles to-parking lot } \\ \text { TOU } & \text { Time of use }\end{array}$




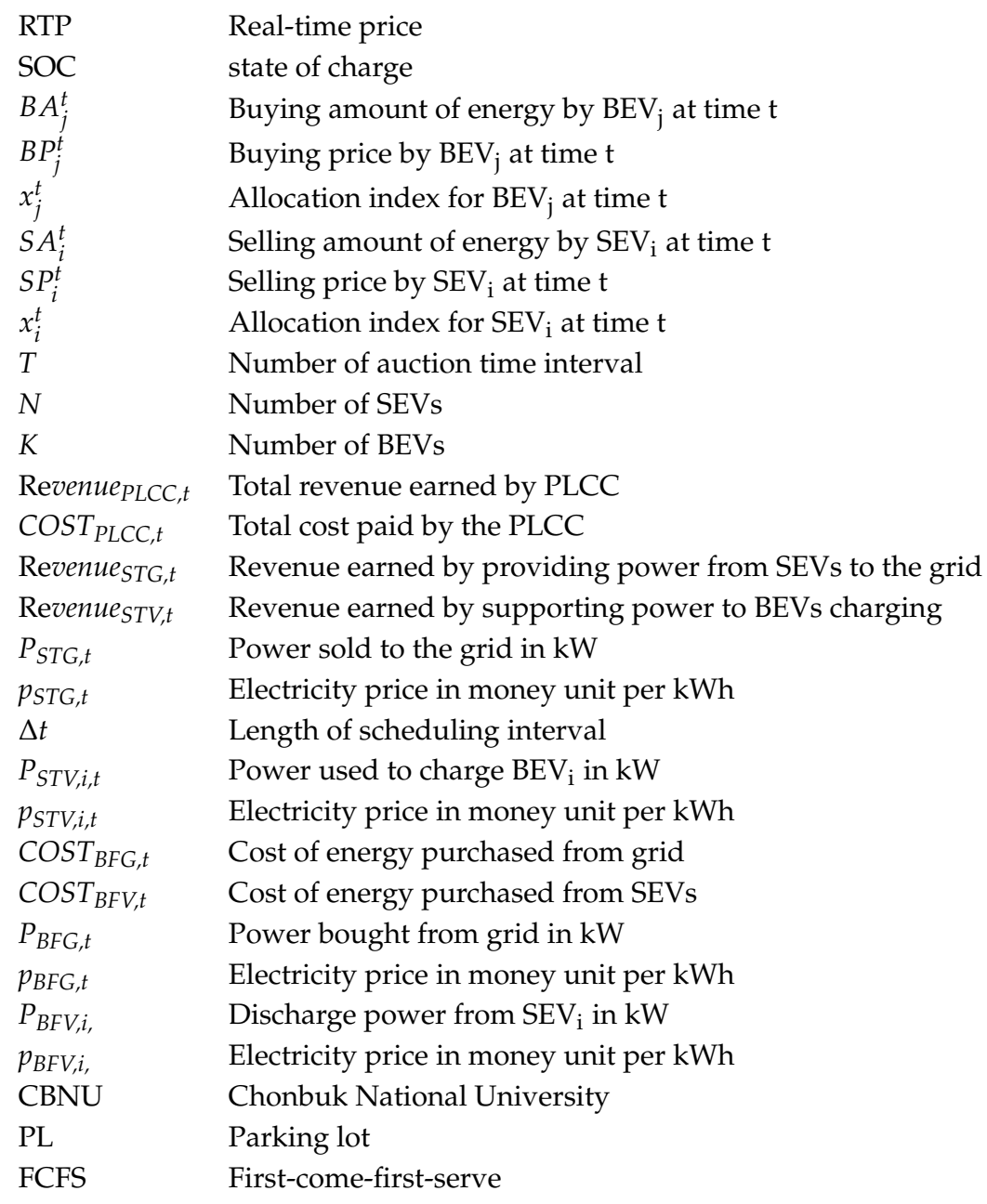

\section{References}

1. Shuai, W.; Maille, P.; Pelov, A. Charging Electric Vehicles in the Smart City: A Survey of Economy-Driven Approaches. IEEE Trans. Intell. Transp. Syst. 2016, 17, 2089-2106. [CrossRef]

2. Park, L.; Lee, S.; Chang, H. A Sustainable Home Energy Prosumer-Chain Methodology with Energy Tags over the Blockchain. Sustainability 2018, 10, 658. [CrossRef]

3. Bayram, I.S.; Shakir, M.Z.; Abdallah, M.; Qaraqe, K. A Survey on Energy Trading in Smart Grid. In Proceedings of the 2014 IEEE Global Conference on Signal and Information Processing (GlobalSIP), Atlanta, GA, USA, 3-5 December 2014; pp. 258-262.

4. Khorasany, M.; Mishra, Y.; Ledwich, G. Peer-to-peer market clearing framework for DERs using knapsack approximation algorithm. In Proceedings of the 2017 IEEE PES Innovative Smart Grid Technologies Conference Europe (ISGT-Europe), Torino, Italy, 26-29 September 2017; IEEE: Piscataway, NJ, USA, 2017; pp. 1-6.

5. Jogunola, O.; Ikpehai, A.; Anoh, K.; Adebisi, B.; Hammoudeh, M.; Gacanin, H.; Harris, G. Comparative Analysis of P2P Architectures for Energy Trading and Sharing. Energies 2017, 11, 62. [CrossRef]

6. Zhang, C.; Wu, J.; Long, C.; Cheng, M. Review of Existing Peer-to-Peer Energy Trading Projects. Energy Procedia 2017, 105, 2563-2568. [CrossRef]

7. Alvaro-Hermana, R.; Fraile-Ardanuy, J.; Zufiria, P.J.; Knapen, L.; Janssens, D. Peer to Peer Energy Trading with Electric Vehicles. IEEE Intell. Transp. Syst. Mag. 2016, 8, 33-44. [CrossRef]

8. Long, C.; Wu, J.; Zhang, C.; Thomas, L.; Cheng, M.; Jenkins, N. Peer-to-peer energy trading in a community microgrid. In Proceedings of the 2017 IEEE Power \& Energy Society General Meeting, Chicago, IL, USA, 16-20 July 2017; IEEE: New York, NY, USA, 2017; pp. 1-5. 
9. Babic, J.; Carvalho, A.; Ketter, W.; Podobnik, V. Evaluating Policies for Parking Lots Handling Electric Vehicles. IEEE Access 2018, 6, 944-961. [CrossRef]

10. Jogunola, O.; Ikpehai, A.; Anoh, K.; Adebisi, B.; Hammoudeh, M.; Son, S.-Y.; Harris, G. State-of-the-Art and Prospects for Peer-to-Peer Transaction-Based Energy System. Energies 2017, 10, 2106. [CrossRef]

11. Smart Grid Reference Architecture, CEN-CENELEC-ETSI Smart Grid Coordination Group, November 2012. Available online: https:/ / ec.europa.eu/energy/sites/ener/files/documents/xpert_group1_reference_ architecture.pdf (accessed on 1 August 2018).

12. Framework for Cyber-Physical Systems. 2016. Available online: https://s3.amazonaws.com/nist-sgcps/ cpspwg/files/pwgglobal/CPS_PWG_Framework_for_Cyber_Physical_Systems_Release_1_0Final.pdf (accessed on 1 August 2018).

13. Mengelkamp, E.; Gärttner, J.; Rock, K.; Kessler, S.; Orsini, L.; Weinhardt, C. Designing microgrid energy markets: A case study: The Brooklyn Microgrid. Appl. Energy 2018, 210, 870-880. [CrossRef]

14. Martello, S.; Toth, P. Knapsack Problems: Algorithms and Computer Implementations; John Wiley \& Amp; Sons, Inc.: New York, NY, USA, 1990; ISBN 0-471-92420-2.

15. Vehicle Fuel Economy and $\mathrm{CO}_{2}$ Emisssions: Data and Analyses. Available online: www.energy.or.kr (accessed on 1 August 2018).

16. Electric Vehicle Charging Tariff. Available online: http.www.kepco.co.kr (accessed on 1 August 2018).

(c) 2018 by the authors. Licensee MDPI, Basel, Switzerland. This article is an open access article distributed under the terms and conditions of the Creative Commons Attribution (CC BY) license (http://creativecommons.org/licenses/by/4.0/). 